\title{
Combination of Gemcitabine and Carboplatin in Urothelial Cancer Patients Unfit for Cisplatin due to Impaired Renal or Cardiac Function
}

\author{
Avishay Sella, Svetlana Kovel \\ Department of Oncology, Assaf Harofeh Medical Center, Zerifin 70300, Israel, affiliated to the Sackler \\ Faculty of Medicine, Tel Aviv University, Ramat Aviv, Israel
}

\section{ABSTRACT}

Purpose: Combination of gemcitabine and carboplatin is the accepted treatment for metastatic urothelial cancer patients unfit for cisplatin-based chemotherapy. Materials and Methods: Gemcitabine $1000 \mathrm{mg} / \mathrm{m}^{2}$ (days 1, 8) and carboplatin AUC4.5 (day 1) were given every 21 days to 23 patients with creatinine clearance $<60$ $\mathrm{mL} / \mathrm{min}$, cardiac ejection fraction $<45 \%$ or active ischemia. Patient characteristics included: median age 73 (56-86) years; primary site: bladder 17 (73\%), upper tract $6(27 \%)$ patients; Bajorin's prognostic groups: good 6 (26\%), intermediate $11(48 \%)$ and poor $6(26 \%)$ patients. Data was retrospectively documented. Patients were followed until they expired.

Results: We obtained objective responses in 8 (34.7\%) patients, (95\% CI, 16.3$57.2 \%)$, including one patient with complete response. The median progressionfree survival was $4(0.2-16.5+)$ months and the overall survival $8.6(0.2-45.3+)$ months. At time of analysis, 4 patients (17\%) remained disease free; 3 of them underwent resection of residual disease. Toxicity included: infection in 9 (39\%) patients; among them, one died from pneumonia; bleeding $\geq$ grade 2 in $3(13 \%)$ patients and fatigue grade 3 in $2(9 \%)$ patients. Hematologic toxicity included grade 4 thrombocytopenia in $2(9 \%)$ patients and grade 4 neutropenia in $3(13 \%)$ patients. Five (22\%) patients discontinued therapy due to toxicity.

Conclusions: Combination of gemcitabine and carboplatin demonstrated clinical activity in patients with advanced urothelial cancer unfit for cisplatin. It was associated with considerable toxicity. Resection of residual disease is feasible in this population.

\section{ARTICLE INFO}

\section{Key words:}

kidney; neoplasms; transitional cell carcinoma; neoplasm

metastasis; carboplatin

Int Braz J Urol. 2012; 38: 49-56

Submitted for publication:

January 05, 2011

Accepted after revision:

June 26, 2011

\section{INTRODUCTION}

Cisplatin-based combination chemotherapy has been the standard of care for metastatic urothelial cancer since the late 1980's (1). However, approximately half of these patients are not eligible for cisplatin-based chemotherapy due to impaired renal function, low performance status or comorbidity and are defined as unfit for cisplatin (1).

The combination of gemcitabine and carboplatin was developed for patients with metastatic transitional cell carcinoma (TCC) of the bladder unfit for cisplatin-based therapy and subsequently was adopted by additional investigators for such patients (2-13). 
Recently, a large randomized phase III trial has established gemcitabine/carboplatin as the standard therapy for patients with metastatic urothelial cancer who are unfit for cisplatin-based therapy. An objective response rate of $41.2 \%$ was observed in 119 patients. The progression-free survival was 5.8 months, and the survival was 9.3 months. Efficacy was affected by the Bajorin risk groups: good prognosis, intermediate and poor prognosis - 12.0, 9.3, and 5.5 months, respectively. Unfortunately, despite a higher response rate than the conventional therapy (carboplatin/vinblastine/methotrexate), the overall survival was similar $(13,14)$.

In the present study, we focus on the effect of this combination in patients unfit for cisplatin due to decreased renal function or cardiac function, thus precluding the necessary forced hydration required for cisplatin therapy, irrespective of performance status and disease extent.

\section{MATERIALS AND METHODS}

\section{Patient Selection}

Patients were required to have histologically proven locally advanced or metastatic urothelial TCC of the urinary tract, not amenable to curative surgical or radiotherapeutic treatment and with measurable disease as defined by the Response Evaluation Criteria in Solid Tumors (14). Ineligibility (unfit) for cisplatin was defined as measured creatinine clearance $<60 \mathrm{~mL} / \mathrm{min}$ or cardiac ejection fraction $<50 \%$ or active cardiac ischemia proven by nuclear studies. Additional eligibility criteria included an estimated life expectancy of at least 12 weeks and Karnofsky performance status score $\geq 40 \%$. Previous treatment with adjuvant or neoadjuvant chemotherapy was allowed if completed more than 6 months before the beginning of the study. Laboratory requirements included adequate bone-marrow (white blood cells $>3500 / \mu \mathrm{L}$, absolute neutrophil count (ANC) $>1.5 \times 10^{3} / \mu \mathrm{L}$ and platelets $>125 \times 10^{3} / \mu \mathrm{L}$ ), bilirubin level $\leq 1.6-7.0 \mathrm{mg} / \mathrm{dL}$ (15). Exclusion criteria included: the presence of brain metastases or other central nervous system lesions; a concomitant malignancy except for cured basal-cell skin cancer or carcinoma in situ of the cervix; and pregnancy. Patients were required to comply with all the requirements of the trial. The study was approved by the Ethics Committee of the center and each patient gave written informed consent before study entry. Response was prospectively documented while toxicity was retrospectively collected.

\section{Therapy}

Patients received gemcitabine at a dose of $1000 \mathrm{mg} / \mathrm{m}^{2}$ as an intravenous infusion over 30 minutes on days 1 and 8, combined with carboplatin $\mathrm{AUC}=4.5$ on day 1 every 3 weeks.

Treatment was continued until detected disease progression or intolerable toxicity. We attempted to deliver at least 6 cycles, with 2 cycles beyond documented complete response.

Cycles were not started unless ANC was $\geq 1.5 \times 10^{3} / \mu \mathrm{L}$ and platelets $\geq 125 \times 10^{3} / \mu \mathrm{L}$. Gemcitabine boosters on day 8 were given with a $50 \%$ dose reduction if granulocytes measured 1,0-1,9 $\times 10^{3} / \mu \mathrm{L}$ and platelets $50-99 \times 10^{3} / \mu \mathrm{L}$. Treatment was withheld with lower values.

If patients required more than 2 weeks for hematologic recovery, or there was grade 4 neutropenia with fever, grade 4 thrombocytopenia for more than 3 days, or thrombocytopenia with active bleeding during the nadir, treatment was continued with 25\% dose-reduction of both drugs. Granulocyte colony-stimulating factors were not routinely used. They were introduced, without treatment dose modification, in the event of prolonged ( $>2$ weeks) neutrophile recovery or grade 4 neutropenia with fever. In the event of subsequent grade 3-4 hematologic toxicity, doses were reduced by $25 \%$. Similar dose modification was utilized for any grade 3-4 non-hematologic toxicity. Only 2 dose modifications were allowed.

\section{Therapy Management \& Assessment}

Toxicity was evaluated using Common Toxicity Criteria, Version 2.0. All patients underwent a complete medical history, physical examination, blood count, blood chemistries and measured creatinine clearance before each treatment cycle. 
Response to treatment was assessed by computed tomography every 2 cycles using Response Evaluation Criteria in Solid Tumors criteria 1.0 (15).

Sample size was based on Response Rate (RR). The smallest response probability (rejected threshold) was set to $20 \%$ ( $\mathrm{p} 0=0.2$ ), as we believed that an RR of at least $20 \%$ would be beneficial to the patient, the largest response probability was based on the assumption that a $40 \%$ response rate - a desirable response $(\mathrm{p} 1=0.4)$, would be detected. According to Simon, the sample size for detection of the desired width of 20\% - 40\% RR (alpha $=0.1$, one tail; beta $=0.2$ ) at the first stage is 23 patients (16). Additional observations included safety and overall survival (16). We report here the results of the first stage.

\section{RESULTS}

During the last 7 years we treated 23 patients who fulfilled the required inclusion crite- ria. The patient characteristics are presented in Table-1.

\section{Treatment Efficacy and Toxicity}

We administered a median of $4(1-6)$ cycles per patient. This resulted in an objective response in 8 (34.7\%) patients, (95\% CI, 16.3 $57.2 \%$ ), including one patient with complete response (CR). Ten patients (43.4\%) obtained stable disease (Table-2). Median progression-free survival was $4(0.2-6.5+)$ months and overall survival was $8.6(0.2-45.3+)$ months (Figure-1). At the time of analysis, 11 (49\%) patients were alive and $4(17 \%)$ patients remained disease-free. Three patients of the latter group underwent resection of viable radiological residual disease: kidney with regional lymph-nodes, pulmonary metastases and abdominal and retroperitoneal tumor masses following laparoscopic nephrectomy.

Analysis according to Memorial Bajorin's prognostic groups revealed that the median

Table 1 - Patient characteristics.

\begin{tabular}{ll}
\hline No patients & $23(100 \%)$ \\
\hline Gender & $15(65 \%)$ \\
Males & $8(35 \%)$ \\
Females & $73(58-86)$ years \\
Age (median) & $80(40-100) \%$ \\
Karnofsky performance status score (median) & \\
Primary site & $17(74 \%)$ \\
Bladder & $6(26 \%)$ \\
Upper tract & $11(48 \%)$ \\
Visceral metastases & \\
Memorial Sloan Kettering prognostic groups & $6(26 \%)$ \\
Good & $11(48 \%)$ \\
Intermediate & $6(26 \%)$ \\
Poor & $53.7(28-92.5)$ \\
Creatinine clearance & \\
&
\end{tabular}


Table 2 - Response rate.

\begin{tabular}{lc}
\hline No patients & $23(100 \%)$ \\
\hline Response & \\
Complete response & $1(4.3 \%)$ \\
Partial response & $7(30.4 \%)$ \\
Objective response & $8(34.7 \%)$ \\
Stable disease & $10(43.4 \%)$ \\
\hline
\end{tabular}

Figure 1 - Survival curve.

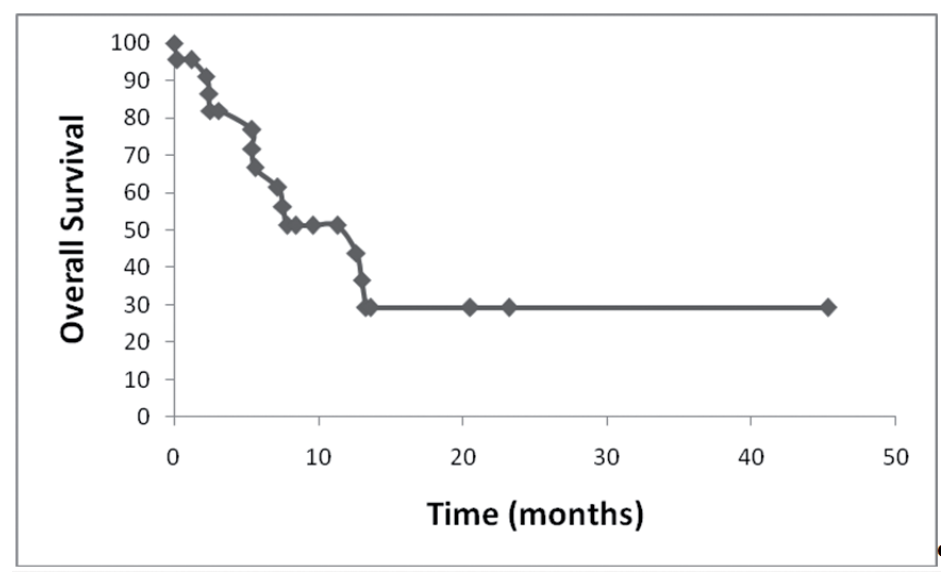

survival of the good prognosis group was 13.6 months $(4.1+-45.3+)$ compared to 5.6 months $(2.4-20.5+)$ in the intermediate prognosis group $(\mathrm{p}=0.0496)$. The median survival of the poor prognosis group was 4.5 months (0.2 - 12.6), which was not statistically significant compared to the intermediate prognosis group ( $p=0.27)$.

Therapy was not devoid of toxicity (Table-3). Nine patients (39\%) developed infection, including one patient who died of pneumonia. This patient had a low performance status (Karnofsky performance status - 40\%) with creatinine clearance of $34 \mathrm{~mL} / \mathrm{min}$. Additional toxicity included: bleeding $\geq$ grade 2 in 3 (13\%) patients, fatigue grade 2 in $5(22 \%)$ patients and fatigue grade 3 in 2 (9\%) patients. Hematologic toxicity occurred as follows: grade 4 thrombocytopenia in $2(9 \%)$ patients and grade 4 neutropenia in 3 (13\%) patients. Median nadir blood counts included: Hg $8.8(6.5-12.1) \mathrm{g} / \mathrm{dL}$, neutrophiles 1,2 $(0.2-9.9) \times 10^{3} / \mu \mathrm{L}$ and platelets $123(2-318) \times$ $10^{3} / \mu \mathrm{L}$. Five (22\%) patients discontinued therapy due to toxicity.

\section{COMMENTS}

Our results with gemcitabine in combination with carboplatin for patients unfit for cisplatin due to renal or cardiac impairments, irrespective of low performance status or disease extent, 
are within the range of previous publications (Table-4) (2-13).

We have also demonstrated a better outcome among Bajorin's good prognosis patients compared to the intermediate and poor prognosis groups. However, the small sample size prevented distinguishable separation between the intermediate and poor prognostic categories $(3,14)$ not allowing a randomized trial study.

These findings re-emphasize the need for personalized therapy for the Bajorin's good prognostic group of the cisplatin-unfit population. This group is characterized by higher treatment efficacy and the lowest toxicity profile with the gemcitabine/carboplatin combination (13). Thus, survival prolongation is a legitimate objective in these patients. Methods to expand the cisplatinbased therapy options in this group should include improving the selection of patients who may safely received cisplatin-based therapy, optimizing the drug administration and developing effective chemo-protective approaches (17).

Various methods for estimating renal function have been explored, many found to be sub-optimal (17). This may explain the widely accepted threshold of $60 \mathrm{~mL} / \mathrm{min}$ creatinine clearance for cisplatin administration. It appears that measured creatinine clearance is more accurate than calculation with the Cockcroft and Gault equations (18). It is conceivable that utilizing measured creatinine clearance, or adminis- tering cisplatin over a longer period, it would be possible to lower this threshold (19).

Non-nephrotoxic regimens have not yet emerged as potential replacements for cisplatinbased therapy in cisplatin-unfit patients. A recent publication of first line therapy with the combination gemcitabine/paclitaxel reported a response rate of 37\%. This trial recruited patients with creatinine clearance $>40 \mathrm{~m} / \mathrm{min}$, which falls within the definition of cisplatin-unfit patients (20). Unfortunately, the authors did not report the efficacy of this regimen in this population.

Despite the low response rate of gemcitabine/carboplatin for the cisplatin-unfit population (Table-4), the acceptable toxicity pattern signals this regimen as a potential therapy for such patients.

Angiogenesis, another non-nephrotoxic treatment alternative, has been shown to be important in the development and progression of urothelial cancer (21). Thus, several trials with sunitinib, sorafenib and pazopanib have been performed (21-24). Sunitinib is preclinically active against urothelial carcinoma (25). When given as second-line therapy after chemotherapy in patients fit for cisplatin, it failed to achieve its initial expectations. However, a clinical benefit was observed in some patients (21). Recently, promising results have been obtained with sunitinib in patients unfit for cisplatin. Of the 21 evaluable patients, 3 (8.1\%) achieved a partial response,

Table 3 - Toxicity rate.

\begin{tabular}{ll}
\hline No patients & $23(100 \%)$ \\
\hline Infection & $9(39 \%)$ \\
Bleeding (grade 2) & $3(13 \%)$ \\
Fatigue & \\
Grade 2 & $5(22 \%)$ \\
Grade 3 & $2(9 \%)$ \\
Hematologic toxicity & \\
Thrombocytopenia grade 4 & $2(9 \%)$ \\
Neutropenia grade 4 & $3(13 \%)$
\end{tabular}


Table 4 - Gemcitabine/carboplatin combination in patients with metastatic urothelial cancer unfit for cisplatin.

\begin{tabular}{|c|c|c|c|c|c|c|c|c|}
\hline \multirow{2}{*}{ Author } & \multirow{2}{*}{ Year } & \multirow{2}{*}{$\begin{array}{l}\text { Regimen } \\
\text { Every } 21 \text { days }\end{array}$} & \multirow{2}{*}{$\begin{array}{l}\text { No } \\
\text { Pts }\end{array}$} & \multirow{2}{*}{$\mathrm{RR}$} & \multirow{2}{*}{$\begin{array}{l}\text { TTP } \\
\text { Mths }\end{array}$} & \multirow{2}{*}{$\begin{array}{c}\text { Survival } \\
\text { Mths }\end{array}$} & \multicolumn{2}{|c|}{ Cisplatin unfit } \\
\hline & & & & & & & $\begin{array}{c}\mathrm{CCT} \\
<60 \mathrm{~mL} / \mathrm{min}\end{array}$ & $\begin{array}{c}\text { PS }<2 \\
\text { or } \\
\text { Karnofsky }<80 \%\end{array}$ \\
\hline Carles et al. (4) & 2000 & $\begin{array}{c}\mathrm{G} 1000 \mathrm{mg} / \mathrm{m}^{2}, \mathrm{~d} 1,8 \\
\text { Carbo AUC 5, d } 1\end{array}$ & 17 & $56 \%$ & 7 & 10 & $100 \%$ & $41.1 \%$ \\
\hline Bellmunt et al. (5) & 2001 & $\begin{array}{l}\mathrm{G} 1000 \mathrm{mg} / \mathrm{m}^{2}, \mathrm{~d} 1,8 \\
\text { Carbo AUC 4.5-5, d } 1\end{array}$ & 16 & $43.7 \%$ & $\mathrm{~N} / \mathrm{A}$ & $\mathrm{N} / \mathrm{A}$ & $75 \%$ & $18.7 \%$ \\
\hline Shannon et al. (6) & 2001 & $\begin{array}{c}\mathrm{G} 1000 \mathrm{mg} / \mathrm{m}^{2}, \mathrm{~d} 1,8 \\
\text { Carbo AUC 5, d } 1\end{array}$ & 17 & $58.8 \%$ & 4.6 & 10.5 & $82 \%$ & $29.4 \%$ \\
\hline Nogué-Aliguer et al. (2) & 2003 & $\begin{array}{c}\mathrm{G} 1000 \mathrm{mg} / \mathrm{m}^{2}, \mathrm{~d} 1,8 \\
\text { Carbo AUC 5, d } 1\end{array}$ & 41 & $56.1 \%$ & 6.2 & 10.1 & $53.7 \%$ & $36.6 \%$ \\
\hline Linardou et al. (3) & 2004 & $\begin{array}{c}\mathrm{G} 1000 \mathrm{mg} / \mathrm{m}^{2}, \mathrm{~d} 1,8 \\
\text { Carbo AUC 4, d } 1\end{array}$ & 56 & $36 \%$ & 4.8 & 7.2 & $68 \%$ & $46 \%$ \\
\hline Helke et al. (7) & 2006 & $\begin{array}{c}\mathrm{G} 1000 \mathrm{mg} / \mathrm{m}^{2}, \mathrm{~d} 1,8 \\
\text { Carbo AUC 4, 5, d } 1\end{array}$ & 30 & $50 \%$ & 5.3 & 13,14 & $50 \%$ & $\mathrm{~N} / \mathrm{A}$ \\
\hline Bamias et al. (8) & 2006 & $\begin{array}{c}\mathrm{G} 1000 \mathrm{mg} / \mathrm{m} 2, \mathrm{~d} 1,8 \\
\text { Carbo AUC 5, d } 1\end{array}$ & 60 & $38.3 \%$ & 7.6 & 16.3 & $21.6 \%$ & $13 \%$ \\
\hline Bamias et al. (9) & 2007 & $\begin{array}{c}\mathrm{G} 1000 \mathrm{mg} / \mathrm{m}^{2}, \mathrm{~d} 1,8 \\
\text { Carbo AUC 5, d } 1\end{array}$ & 34 & $24 \%$ & $4.4^{\mathrm{a}}$ & 9.8 & $100 \%$ & $68 \%$ \\
\hline Xu et al. (10) & 2007 & $\begin{array}{c}\mathrm{G} 1200 \mathrm{mg} / \mathrm{m}^{2}, \mathrm{~d} 1,8 \\
\text { Carbo AUC 5, d } 1\end{array}$ & 39 & $46.2 \%$ & 7.5 & 13.6 & $19.5 \%$ & $12.2 \%$ \\
\hline Dogliotti et al. (11) & 2007 & $\begin{array}{c}\mathrm{G} 1250 \mathrm{mg} / \mathrm{m}^{2}, \mathrm{~d} 1,8 \\
\text { Carbo AUC 5, d } 2\end{array}$ & 39 & $56.4 \%$ & 6.9 & 9.8 & $0 \%$ & $14.5 \%$ \\
\hline Hudson \& Lester (12) & 2008 & $\begin{array}{c}\mathrm{G} 1200 \mathrm{mg} / \mathrm{m}^{2}, \mathrm{~d} 1,8 \\
\text { Carbo AUC 5-6, d } 1\end{array}$ & 15 & $67 \%$ & $\mathrm{~N} / \mathrm{A}$ & 9 & $\mathrm{~N} / \mathrm{A}$ & $20 \%$ \\
\hline De Santis et al. (13) & 2010 & $\begin{array}{c}\mathrm{G} 1000 \mathrm{mg} / \mathrm{m}^{2}, \mathrm{~d} 1,8 \\
\text { Carbo AUC 4, 5, d } 1\end{array}$ & 119 & $41.2 \%$ & $5.8^{\mathrm{a}}$ & 9.3 & $86.4 \%$ & $40.9 \%$ \\
\hline Current series & 2010 & $\begin{array}{c}\mathrm{G} 1000 \mathrm{mg} / \mathrm{m}^{2}, \mathrm{~d} 1,8 \\
\text { Carbo AUC 4, 5, d } 1\end{array}$ & 23 & $34.7 \%$ & $4^{a}$ & 8.6 & $78 \%$ & $43.4 \%$ \\
\hline
\end{tabular}

$\mathbf{G}=$ Gemcitabine Carbo = Carboplatin $\mathbf{C C T}=$, Creatinine clearance time; $\mathbf{R R}=$ Objective response rate; $\mathbf{P S}=$ WHO performance status; TTP = time to disease progression. 
and an additional $14(53.8 \%)$ patients had prolonged ( $>3$ months) stable disease, with clinical benefits to $62 \%$ and a progression-free survival of 5.9 month (22). This is within the efficacy range of gemcitabine/carboplatin regimens (Table-4). A potential approach is a sequential combination of sunitinib to patients who have not progressed on gemcitabine/carboplatin therapy. Preliminary data suggested that such a scheme is feasible in fit-forcisplatin-based therapy patients (26).

In our experience, the therapy with gemcitabine in combination with carboplatin was associated with significant toxicity. Our sample size prevented a reliable statistical categorization according to Bajorin prognostic factors. However, a larger trial with this combination demonstrated recently that toxicity was the lowest in the Bajorin good prognostic group. This suggests that with the lack of more effective and less toxic therapeutic options, gemcitabine/carboplatin therapy should be limited to patients with Bajorin good prognostic group. Therapy with poor prognostic features should focus on palliative endpoints, while therapy in the intermediate group should be determined on a case by case review.

Finally, 3 of our long-term survivors who achieved a partial response to therapy underwent resection of residual disease. Our data suggested that this is feasible also in cisplatin-unfit patients (27).

\section{CONCLUSIONS}

Our experience with the gemcitabine/carboplatin combination is within the range of the published data. This regimen is active mostly in the Bajorin's good prognosis group. It is associated with considerable toxicity. Patients with a partial response should be considered for resection of residual disease.

\section{ABBREVIATIONS}

ANC $=$ absolute neutrophil count

Carbo $=$ carboplatin

$\mathrm{CCT}=$ creatinine clearance time

$\mathrm{CR}=$ complete response

$\mathrm{G}=$ gemcitabine

PS $=$ WHO performance status
$\mathrm{RR}=$ response rate

TCC $=$ transitional cell carcinoma

TTP $=$ time to disease progression

\section{CONFLICT OF INTEREST}

None declared.

\section{REFERENCES}

1. Stenzl A, Cowan NC, De Santis M, Jakse G, Kuczyk MA, Merseburger AS, et al.: The updated EAU guidelines on muscle-invasive and metastatic bladder cancer. Eur Urol. 2009; 55: 815-25.

2. Nogué-Aliguer M, Carles J, Arrivi A, Juan 0, Alonso L, Font A, et al.: Gemcitabine and carboplatin in advanced transitional cell carcinoma of the urinary tract: an alternative therapy. Cancer. 2003; 97: 2180-6.

3. Linardou H, Aravantinos G, Efstathiou E, Kalofonos C, Anagnostopoulos A, Deliveliotis C, et al.: Gemcitabine and carboplatin combination as first-line treatment in elderly patients and those unfit for cisplatin-based chemotherapy with advanced bladder carcinoma: Phase II study of the Hellenic Co-operative Oncology Group. Urology. 2004; 64: 479-84.

4. Carles J, Nogué $M$, Domènech $M$, Pérez $C$, Saigí $E$, Villadiego $\mathrm{K}$, et al.: Carboplatin-gemcitabine treatment of patients with transitional cell carcinoma of the bladder and impaired renal function. Oncology. 2000; 59: 24-7.

5. Bellmunt J, de Wit R, Albanell J, Baselga J: A feasibility study of carboplatin with fixed dose of gemcitabine in "unfit" patients with advanced bladder cancer. Eur J Cancer. 2001; 37 2212-5.

6. Shannon C, Crombie C, Brooks A, Lau H, Drummond M, Gurney $\mathrm{H}$ : Carboplatin and gemcitabine in metastatic transitional cell carcinoma of the urothelium: effective treatment of patients with poor prognostic features. Ann Oncol. 2001; 12: $947-52$.

7. Helke C, May M, Hoschke B: Gemcitabine and carboplatin chemotherapy in advanced transitional cell carcinoma in regard to patients with impaired renal function. Aktuelle Urol. 2006; 37: 363-8.

8. Bamias A, Moulopoulos LA, Koutras A, Aravantinos G, Fountzilas $G$, Pectasides D, et al.: The combination of gemcitabine and carboplatin as first-line treatment in patients with advanced urothelial carcinoma. A Phase II study of the Hellenic Cooperative Oncology Group. Cancer. 2006; 106: 297-303.

9. Bamias A, Lainakis G, Kastritis E, Antoniou N, Alivizatos $G$, Koureas $A$, et al.: Biweekly carboplatin/gemcitabine in patients with advanced urothelial cancer who are unfit for cisplatin-based chemotherapy: report of efficacy, quality of life and geriatric assessment. Oncology. 2007; 73: 290-7. 
10. Xu N, Zhang XC, Xiong JP, Fang WJ, Yu LF, Qian J, et al.: A phase II trial of gemcitabine plus carboplatin in advanced transitional cell carcinoma of the urothelium. BMC Cancer. 2007; 7: 98.

11. Dogliotti $L$, Cartenì $G$, Siena $S$, Bertetto 0 , Martoni $A$, Bono A, et al.: Gemcitabine plus cisplatin versus gemcitabine plus carboplatin as first-line chemotherapy in advanced transitional cell carcinoma of the urothelium: results of a randomized phase 2 trial. Eur Urol. 2007; 52: 134-41.

12. Hudson E, Lester JF: Gemcitabine and carboplatin in the treatment of transitional cell carcinoma of the urothelium: a single centre experience and review of the literature. Eur $\mathrm{J}$ Cancer Care (Engl). 2010; 19: 324-8.

13. De Santis M, Bellmunt J, Mead G, Kerst JM, Leahy M, Maroto $\mathrm{P}$, et al.: Randomized phase II/III trial assessing gemcitabine/ carboplatin and methotrexate/carboplatin/vinblastine in patients with advanced urothelial cancer "unfit" for cisplatin-based chemotherapy: phase II--results of EORTC study 30986. J Clin Oncol. 2009; 27: 5634-9.

14. Bajorin DF, Dodd PM, Mazumdar M, Fazzari M, McCaffrey $\mathrm{JA}$, Scher HI, et al.: Long-term survival in metastatic transitional-cell carcinoma and prognostic factors predicting outcome of therapy. J Clin Oncol. 1999; 17: 3173-81.

15. Therasse P, Arbuck SG, Eisenhauer EA, Wanders J, Kaplan RS, Rubinstein L, et al.: New guidelines to evaluate the response to treatment in solid tumors. European Organization for Research and Treatment of Cancer, National Cancer Institute of the United States, National Cancer Institute of Canada. J Natl Cancer Inst. 2000; 92: 205-16.

16. Simon R: Optimal two-stage designs for phase II clinical trials. Control Clin Trials. 1989; 10: 1-10.

17. Dash A, Galsky MD, Vickers AJ, Serio AM, Koppie TM, Dalbagni $G$, et al.: Impact of renal impairment on eligibility for adjuvant cisplatin-based chemotherapy in patients with urothelial carcinoma of the bladder. Cancer. 2006; 107: 506-13.

18. McDermott DF, Galindo A, Sherman RL, Jaffe EA, Coleman $\mathrm{M}$, Pasmantier MW: Inadequacy of predicted creatinine clearance as guide to chemotherapy. Cancer Treat Rep. 1987; 71: 1067-9.

19. Carles J, Suárez C, Mesía C, Nogué M, Font A, Doménech M, et al.: Feasiblity study of gemcitabine and cisplatin administered every two weeks in patients with advanced urothelial tumors and impaired renal function. Clin Transl Oncol. 2006; 8: $755-7$.
20. Calabrò F, Lorusso V, Rosati G, Manzione L, Frassineti L, Sava $\mathrm{T}$, et al.: Gemcitabine and paclitaxel every 2 weeks in patients with previously untreated urothelial carcinoma. Cancer. 2009; 115: 2652-9.

21. Gallagher DJ, Milowsky MI, Gerst SR, Ishill N, Riches J, Regazzi $A$, et al.: Phase II study of sunitinib in patients with metastatic urothelial cancer. J Clin Oncol. 2010; 28: 1373-9.

22. Bellmunt J, Gonzalez-Larriba JL, Maroto JP, Carles J, Castellano DE, Mellado B, et al.: First-line treatment with sunitinib monotherapy in patients with advanced urothelial cancer ineligible for cisplatin-based chemotherapy: Pretreatment levels of IL8 and Hounsfield units as predictors of clinical benefit. J Clin Oncol 2010; 28(Suppl 15): abstract 4540.

23. Sridhar SS, Winquist E, Eisen A, Hotte SJ, McWhirter E, Tannock IF, et al.: A phase II trial of sorafenib in first-line metastatic urothelial cancer: a study of the PMH Phase II Consortium. Invest New Drugs. 2011; 29: 1045-9.

24. Vaishampayan U: Systemic therapy of advanced urothelial cancer. Curr Treat Options Oncol. 2009; 10: 256-66.

25. Sonpavde G, Jian W, Liu H, Wu MF, Shen SS, Lerner SP: Sunitinib malate is active against human urothelial carcinoma and enhances the activity of cisplatin in a preclinical model. Urol Oncol. 2009; 27: 391-9.

26. Bradley D, Daignault S, Smith DC, Nanus D, Tagawa S, Stadler WM: Maintenance sunitinib postchemotherapy (CT) in patients (pts) with advanced urothelial carcinoma (UC): A randomized placebo controlled phase II trial. J Clin Oncol 2009; (Suppl 15): abstract 5073.

27. de Vries RR, Nieuwenhuijzen JA, Meinhardt W, Bais EM, Horenblas S: Long-term survival after combined modality treatment in metastatic bladder cancer patients presenting with supra-regional tumor positive lymph nodes only. Eur $\mathrm{J}$ Surg Oncol. 2009; 35: 352-5.

Correspondence address: Dr. Avishay Sella Department of Oncology Assaf Harofeh Medical Center Zerifin, 70300, Israel Fax: + 9728 977-9714 E-mail:a_sella@asaf.health.gov.il 